Article

\title{
mCherry-Labeled Verticillium dahliae Could Be Utilized to Investigate Its Pathogenicity Process in Nicotiana benthamiana
}

\author{
Xiaofeng Su ${ }^{1,+}$, Guoqing Lu ${ }^{1,+}$, Latifur Rehman ${ }^{1,2}$, Xiaokang Li ${ }^{1}$, Lu Sun ${ }^{1,3}$, Huiming Guo ${ }^{1}$ \\ and Hongmei Cheng ${ }^{1, *}$ \\ 1 Biotechnology Research Institute, Chinese Academy of Agricultural Sciences, Beijing 100081, China; \\ suxiaofeng@caa.cn (X.S.); luguoqing007@163.com (G.L.); latif_ibge@yahoo.com (L.R.); \\ lixiaokang2016@163.com (X.L.); sunny_sunlu@126.com (L.S.); guohuiming@caas.cn (H.G.) \\ 2 Department of Biotechnology, The University of Swabi, Khyber Pakhtunkhwa 23561, Pakistan \\ 3 College of Life Engineering, Shenyang Institute of Technology, Fushun 113122, China \\ * Correspondence: chenghongmei@caas.cn; Tel.: +86-10-82106125 \\ + These authors contributed equally to this work.
}

Received: 18 September 2018; Accepted: 16 October 2018; Published: 18 October 2018

\begin{abstract}
Verticillium dahliae is a soil-borne phytopathogenic fungus that causes a destructive vascular wilt, but details of the molecular mechanism behind its pathogenicity are not very clear. Here, we generated a red fluorescent isolate of $V$. dahliae by protoplast transformation to explore its pathogenicity mechanism, including colonization, invasion, and extension in Nicotiana benthamiana, using confocal microscopy. The nucleotide sequences of $m$ Cherry were optimized for fungal expression and cloned into pCT-HM plasmid, which was inserted into $V$. dahliae protoplasts. The transformant $(V d-m)$ shows strong red fluorescence and its phenotype, growth rate, and pathogenicity did not differ significantly from the wild type $V$. dahliae $(V d-w t)$. Between one and three days post inoculation (dpi), the $V d-m$ successfully colonized and invaded epidermal cells of the roots. From four to six dpi, hyphae grew on root wounds and lateral root primordium and entered xylem vessels. From seven to nine dpi, hyphae extended along the surface of the cell wall and massively grew in the xylem vessel of roots. At ten dpi, the $V d-m$ was found in petioles and veins of leaves. Our results distinctly showed the pathway of $V$. dahliae infection and colonization in $N$. benthamiana, and the optimized expression can be used to deepen our understanding of the molecular mechanism of pathogenicity.
\end{abstract}

Keywords: Verticillium dahliae; mCherry; pathogenic process; Nicotiana benthamiana

\section{Introduction}

Verticillium wilt, caused by Verticillium dahliae, is the most dangerous threat to hundreds of dicotyledonous plant species, including a wide range of vegetables, crops and woody plants [1]. As a soil-borne fungus, $V$. dahliae produces abundant microsclerotia to resist adverse conditions and thus survive for many years in soil $[2,3]$. It is mainly disseminated via infected plant material, but once established in a field, it is further spread by the movement of soil through cultivation, wind, and water [4,5]. Although enormous energy has been spent investigating its pathogenicity mechanism and developing resistant cultivars, there is no effective means to protect and treat agricultural fields against this fungus [6-8]. Because annual economic losses can reach nearly 250-310 million United States (US) dollars [9], it is imperative that we better understand the infection process and different developmental stages of $V$. dahliae in order to develop novel control strategies for this devastating disease.

Previous studies have shown that the infection and colonization processes are extremely complicated in field soil [10-12]. The microsclerotium can repeatedly germinate and sporulate in 
a moist environment up to nine times, with higher sporulation when nutrients are present in the soil [3]. The germ tube grows and attaches to the root surface of both resistant and susceptible cultivars [13,14]. Some hyphae can penetrate the roots of susceptible cultivars [15]; then, they rapidly grow and accumulate in the vascular bundles in roots, stems, and leaves of plants, which can block the transport of water and nutrients and result in the stunting, necrosis, wilt, and finally death of the host [11]. The progress of the pathogen through the hosts (e.g., lettuce, Arabidopsis thaliana, sunflower, Cotinus coggygria, and cotton) can be observed and tracked clearly using fluorescently labeled $V$. dahliae and laser scanning confocal microscopy (LSCM) [12,16-19].

Fluorescent proteins have been widely used as visual, nondestructive molecular markers to study gene expression and regulation and interactions between target proteins and monitor the interaction between the host and fungus and the effects of the fungus on plants in real time, especially for soil-borne fungi [20-24]. In general, the green fluorescent protein (GFP) from Aquoria victoria and red fluorescent protein (DsRed, RFP) from Discosoma sp. have been most used as the reporter proteins [25]. The infection route was followed in Arabidopsis and barley using Fusarium strain transformed with GFP [26]. The GFP screening method was used to assess the interaction between microorganisms and Dothistroma septosporum and select fungistatic isolates [27]. GFP-expressing Fusarium oxysporum was also used to visualize colonization of cabbage roots to detect any differences between resistant and susceptible cultivars [28]. In our previous study, we used a GFP-tagged stt3 mutant and wild-type $V$. dahliae to study the infection process in Nicotiana benthamiana in vivo [29]. DsRed gene was stably inserted into Herbaspirillum seropedicae and F. oxysporum to analyze the interaction with the host [30,31] and into F. graminearum to observe the infection process in wheat [32].

On the basis of fungal codon preference, the $m$ Cherry gene can be codon-optimized by introducing various mutations to the amino acid sequence, which yields a protein that matures more completely and has a stronger red fluorescence [33]. To clearly follow the pathogenic process of $V$. dahliae in $N$. benthamiana, here we (1) optimized the coding sequence (CDS) of $m$ Cherry in $V$. dahliae and (2) generated an isolate of $V$. dahliae isolate that highly expressed the $m C h e r r y$ gene so that (3) we could follow the invasion, colonization, and germination of $V$. dahliae in N. benthamiana, and (4) quantified the fungal biomass in different tissues and infection stages.

\section{Materials and Methods}

\subsection{Plants and Fungal Strain}

Seeds of N. benthamiana were surface-sterilized and sown on Murashige and Skoog (MS) agar (PhytoTechnology Laboratories, Lenexa, KS, USA). Seedlings with two leaves were individually transplanted into plastic pots with disinfested soil (1:1 peat compost to vermiculite). Subsequently, the seedlings were incubated in the greenhouse $\left(23 \pm 2{ }^{\circ} \mathrm{C}, 75 \pm 5 \%\right.$ relative humidity, $16 \mathrm{~h} \mathrm{light} / 8 \mathrm{~h}$ dark) and inoculated with fungal suspension liquid when they had eight leaves.

Wild-type $V$. dahliae V991 ( $V d-w t)$, a highly virulent and defoliating pathotype, was obtained from Guiliang Jian at the Institute of Plant Protection, Chinese Academy of Agricultural Sciences (CAAS).

\subsection{Codon Optimization of $m$ Cherry and Construction of Expression Plasmid}

The coding sequence of the mCherry gene was optimized based on fungal codon bias and synthesized by Oligobio, Beijing, China [34,35]. The sequence of the $\operatorname{Tr} p C$ promoter $(\operatorname{Tr} p C \mathrm{P})$ and $\operatorname{Tr} p C$ terminator (TrpC T) from Aspergillus nidulans were amplified by two sets of primer pairs (Ptrpc and Ttrpc; see Table 1 for all primers). The optimized CDS of $m$ Cherry was amplified by primer pair Pmch. For the development of the $m$ Cherry expression cassette, three fragments (promoter, CDS of $m$ Cherry, and terminator) were fused by overlap extension polymerase chain reaction (PCR). Plasmid pCT-hyg harboring a hygromycin (Hyg)-resistance cassette (hpt gene) was kindly provided by Xiaofeng Dai at the Institute of Food Science and Technology, CAAS. The fused fragment was introduced into pCT-hyg by HindIII and XbaI restriction enzymes, and named pCT-HM. 
Table 1. Primers used in this study

\begin{tabular}{|c|c|}
\hline Primers & Sequence $\left(5^{\prime}-3^{\prime}\right)$ \\
\hline \multirow{2}{*}{ Ptrpc } & atc $A A G C T T T T G A A G G A G C A T T T T T G G G C T T G G C$ \\
\hline & CTCGCCCTTGGAGACCATGGTGGCATCGATGCTTGGGTAG \\
\hline \multirow{2}{*}{ Pmch } & ATGGTCTCCAAGGGCGAGGAGGACAAC \\
\hline & CTACTTGTAGAGCTCGTCCATGCCGCC \\
\hline \multirow{2}{*}{ Ttrpc } & CATGGACGAGCTCTACAAGTAGAGTAGATGCCGACCGGGATCC \\
\hline & aacTCTAGATTATCTTTGCGAACCCAGGGGCTG \\
\hline \multirow{2}{*}{ qRT-VdITS } & CCGCCGGTCCATCAGTCTCTCTGTTTATAC \\
\hline & CGCCTGCGGGACTCCGATGCGAGCTGTAAC \\
\hline \multirow{2}{*}{ qRT-Nbactin } & GGACCTTTATGGAAACATTGTGCTCAGT \\
\hline & CCAAGATAGAACCTCCAATCCAGACAC \\
\hline \multirow{2}{*}{ Det-hpt } & GAGGGCGAAGAATCTCGTGCTTTCA \\
\hline & TGTTATGCGGCCATTGTCCGTCAGG \\
\hline \multirow{2}{*}{ Det-mch } & CTACGTTAAGCACCCCGCCGACATT \\
\hline & CTGCTCGACAATCGTGTAGTCCTCGT \\
\hline
\end{tabular}

Underlined sequences were designed based on the mCherry coding sequences (CDS) following the overlap extension polymerase chain reaction (PCR). Restriction sites according to the plasmid pCT-hyg are in bold italic letters, and oligonucleotides for enzyme digestion are in lower-case letters.

\subsection{Fungal Transformation}

Protoplasts were prepared and transformed using a modified protocol [36]. Fungal spores were harvested from potato dextrose agar (PDA) using a $40 \mu \mathrm{m}$ nylon filter and adjusted to $10^{6} / \mathrm{mL}$ in a final concentration. After $20 \mathrm{~h}$ of culturing in a liquid complete medium $(\mathrm{CM})$ at $25^{\circ} \mathrm{C}$, the mycelia were collected on a filter to eliminate nongerminated spores. Mycelia were then digested with $20 \mathrm{mg} / \mathrm{mL}$ of Driselase solution (Sigma Aldrich, St. Louis, MO, USA) in $0.7 \mathrm{M} \mathrm{NaCl}$ at $33^{\circ} \mathrm{C}$. After $3 \mathrm{~h}$, the mycelia were collected as before, and the solution with the protoplasts was centrifuged at $4000 \mathrm{rpm}$ for 10 $\mathrm{min}$. The protoplasts were then resuspended in an STC buffer $(20 \%$ sucrose, $10 \mathrm{mM}$ Tris- $\mathrm{HCl} \mathrm{pH} 8.0$, and $\left.50 \mathrm{mM} \mathrm{CaCl}_{2}\right)$, and $12 \mu \mathrm{g} \mathrm{pCT-HM}$ was added to $200 \mu \mathrm{L}$ of this protoplast solution $\left(10^{6} / \mathrm{mL}\right)$ with $60 \%$ PEG4000, followed by incubation at $25^{\circ} \mathrm{C}$ for $20 \mathrm{~h}$. Protoplasts were then observed for red fluorescence with a laser scanning confocal microscope (LSCM; excitation $555 \mathrm{~nm}$, emission $630 \mathrm{~nm}$; Zeiss LSM 700, Jena, Germany), and the transformants were then transferred to PDA plates with hygromycin B $(50 \mu \mathrm{g} / \mathrm{mL})$.

\subsection{Screening of mCherry-Labeled Verticillium dahliae (Vd-m)}

After one week at $25{ }^{\circ} \mathrm{C}$ on the selective medium, fungal transformants were examined by LSCM. Fungal colonies that expressed red fluorescence were further cultured in liquid CM for genomic DNA extraction. Positive transformants $(V d-m)$ for $h p t$ and $m$ Cheery were confirmed by PCR using two pairs of primers, Det-hpt and Det-mch (Table 1). Wild-type $V$. dahliae ( $V d-w t$ ) and $\mathrm{H}_{2} \mathrm{O}$ were used as negative controls. For assessing the stability of $m C h e r r y$, single-spore isolates of the $V d-m$ strains were subcultured for more than six generations, with LSCM observations and PCR assays of each generation.

\subsection{Characterization of $V d-m$}

Spore suspensions $\left(10 \mu \mathrm{L}, 10^{6} / \mathrm{mL}\right)$ of strain $V d$ - $w t$ and $V d-m$ were placed on respective PDA plates and incubated at $25^{\circ} \mathrm{C}$ for two weeks. Colony diameters were measured every two days. Moreover, the spore suspension $\left(10^{6}\right.$ spores $\left./ \mathrm{mL}\right)$ of strain $V d$ - $w t$ and $V d-m$ was cultured in liquid Czapek-Dox at $200 \mathrm{rpm}$ and $25^{\circ} \mathrm{C}$ in shaker for one week. Spores were counted every day.

\subsection{Plant Inoculation}

The roots of seedlings with eight leaves were immersed in a suspension of $10^{7}$ spores $/ \mathrm{mL}$ of $V d-m$ (or $V d$-wt as the control) for two min, then plants were replanted into new pots. From eight to ten days post-inoculation (dpi), the disease index of five inoculated seedlings was recorded, and the 
phenotype was observed after 12 days, as previously described [9]. Three independent replications were completed.

\subsection{Microscopic Observation of Pathogenic Process}

From one to ten dpi, two inoculated seedlings were removed from the soil, and roots were gently washed in distilled water to remove soil and unattached spores. Roots were fixed into $10 \%$ agarose and sectioned with a knife blade. The slices were placed on a slide with one drop of distilled water and covered with coverslip for microscopic examination, as described above. All experiments were done three times.

\subsection{Quantification of Fungal Biomass}

In order to investigate the infection process at different stages, the fungal biomass was quantified in terms of DNA level by means of quantitative real time polymerase chain reaction (qRT-PCR) and a 7500 Fast Real Time PCR System (ABI, Waltham, MA, USA) [29,37]. At six, eight, and ten dpi, five inoculated seedlings were processed as previously described. The roots, stems, and leaves were removed and grinded into powder for genomic DNA extraction using the Plant Genomic DNA Kit (DP320, TIANGEN, Beijing, China). Primer pair qRT-VdITS was used to amplify ITS1 and ITS2 of ribosomal DNA (Z29511). The N. benthamiana housekeeping gene (Nbactin, JQ256516) was amplified using a primer set of qRT-Nbactin as an endogenous control. The primers are listed in Table 1.

\subsection{Statistical Analysis}

To ensure the authenticity and reliability of the data, the experiments were independently completed in three sets. In addition, the data were analyzed using SPSS Statistics 17.0 software (SPSS, Chicago, IL, USA). Significant differences among the treatment groups were determined with a least significant difference (LSD) procedure $(p<0.01)$.

\section{Results}

\subsection{Optimization of mCherry Gene and Plasmid Construction}

In order to achieve an effective gene expression and strong red fluorescence in $V$. dahliae, we optimized the mCherry CDS based on the codon preference of filamentous fungi. The CDS encodes a protein of 236 amino acids (aa), consistent with the original sequence ( $100 \%$ overall identity) (Figure S1). The $m$ Cherry gene was expressed under the constitutive promoter of $\operatorname{Tr} p C$ from A. nidulans, and to stimulate strong expression, the Kozak sequence was also inserted. The $m C h e r r y$ expression cassette (1582 bp) was amplified by PCR and introduced into pCT-HM plasmid, which harbors hpt as a selection marker (Figure 1).

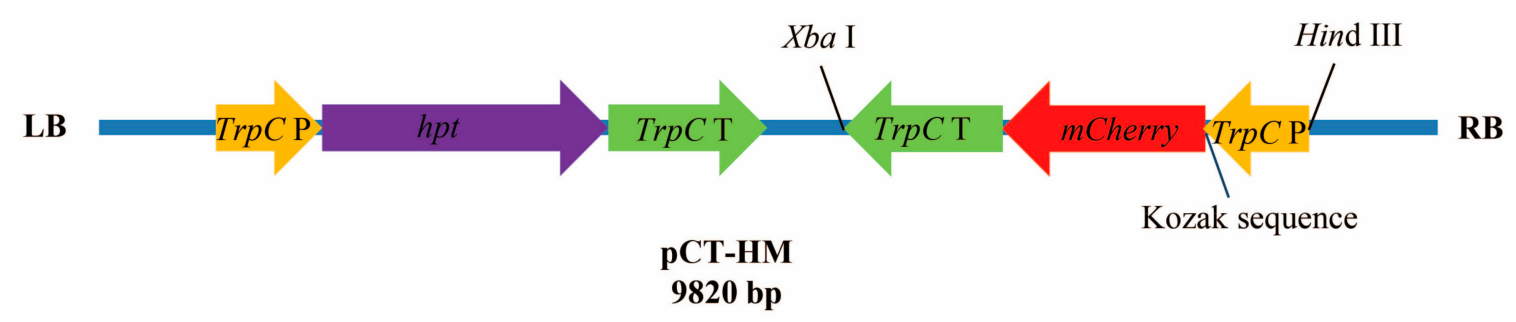

Figure 1. Schematic representation of pCT-HM used for transformation. The mCherry and hpt genes were under the control of the $\operatorname{Tr} p C$ promoter $(\operatorname{Tr} p C \mathrm{P})$ and terminator $(\operatorname{Tr} p C \mathrm{~T}) . \mathrm{P}=$ promoter; $\mathrm{T}=$ terminator.

\subsection{Confirmation of $V d-m$ Isolates}

After construction of plasmid pCT-HM and protoplast transformation, the $V$. dahliae transformants cultured on PDA with hygromycin were screened using LSCM. The hyphae and spores of five of 
46 transformants uniformly displayed strong red fluorescence, and PCR further confirmed the presence of the 549-bp hpt fragment and the 427-bp mCherry fragment (Figure 2 and S2), indicating a successful integration of exogenous transfer-DNA into the $V$. dahliae genomic DNA. The PCR of wt and $\mathrm{H}_{2} \mathrm{O}$ controls was negative for both fragments. Moreover, stable inheritance of $m$ Cherry was confirmed by the generation of red fluorescence for six successive rounds of selection. Subsequently, positive transformants with intense red fluorescence were named as $V d-m$ (Figure 2).

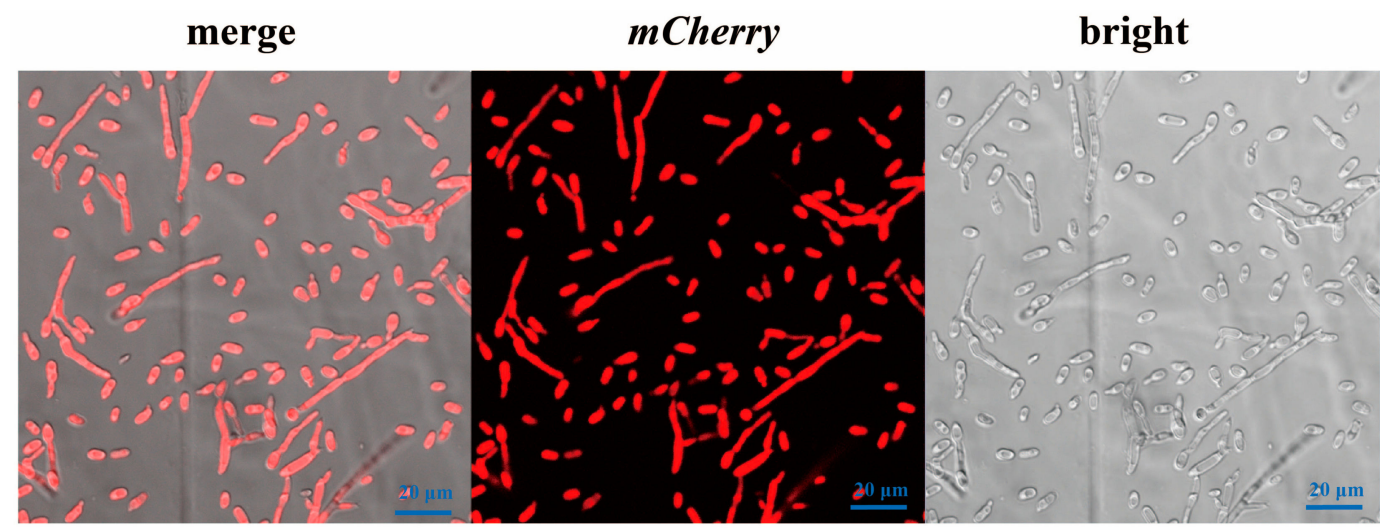

Figure 2. Confocal micrograph of red fluorescence by mCherry-labeled Verticillium dahliae (Vd-m).

\subsection{Analysis of Biological Characteristics of Vd-m}

Growth characteristics and disease severity were compared between $V d-m$ and $V d$-wt (Figure 3 and Figure S3). After two weeks of culture on PDA, the $V d-m$ and $V d$-wt strains were similar in colony diameter and growth rate (Figure 3 and Figure S3a). When cultured in liquid Czapek-Dox, both strains produced similar numbers of spores on a daily basis (Figure S3b). At ten dpi of $N$. benthamiana seedlings with either $V d-m$ or $V d-w t$ strains, all plants had completely wilted (Figure 3). Moreover, the disease severity at eight toten dpi did not differ obviously (Figure S3c). Overall, our results confirmed that $V d-m$ was similar to $V d-w t$ in its biological characteristics, including pathogenesis, and could be used to study the pathogenic process in N. benthamiana.

$V d-w t$

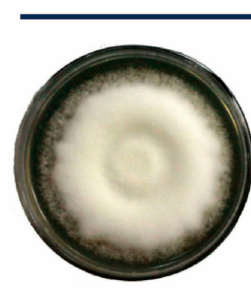

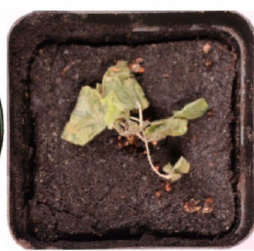
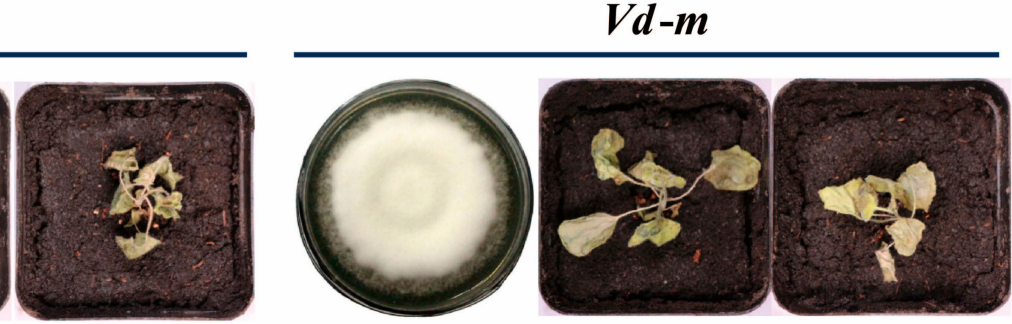

Figure 3. Fungal morphology on potato dextrose agar (PDA) plates and disease symptoms on $N$. benthamiana ten days after inoculation with strain $V d-m$ or $V d-w t$.

\subsection{Attachment and Colonization of Vd-m on Roots}

To understand initial infection by $V$. dahliae, we observed roots at one to three days after inoculation with a $V d-m$ strain (Figure 4). At one dpi, spores were present on the root surface at random sites (Figure $4 a, b)$. At two dpi, the spores had begun to germinate, and germ tubes were observed (Figure $4 c, d$ ). At three dpi, the germ tubes continued to elongate and had undergone cell division to form hyphae (Figure 4e). By three days after inoculation, $V$. dahliae ended the attachment and colonization process on the root surfaces. 

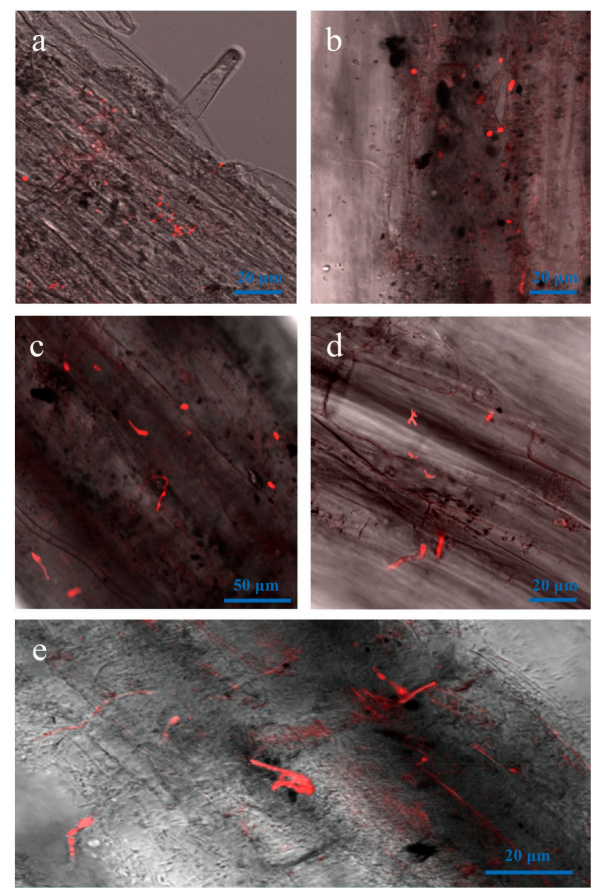

Figure 4. Laser scanning confocal microscope (LSCM) of root surface of Nicotiana benthamiana from one to three days after inoculation with the $V d-m$ strain. $(\mathbf{a}, \mathbf{b})$ Spores at one dpi; (c,d) Germ tubes at two dpi; (e) Elongating hyphae at three dpi.

\subsection{Advanced Penetration Stage of Vd-m in Roots}

By four dpi, hyphal colonization was dense at infection sites, and hyphae had invaded the vascular bundle (Figure 5). Hyphae had also entered the root through wounds and lateral root primordium (Figure 5a,b) and had entered the root xylem vessels and cortical cell junctions (Figure 5c,d). By six dpi, the lower leaves had turned yellow.
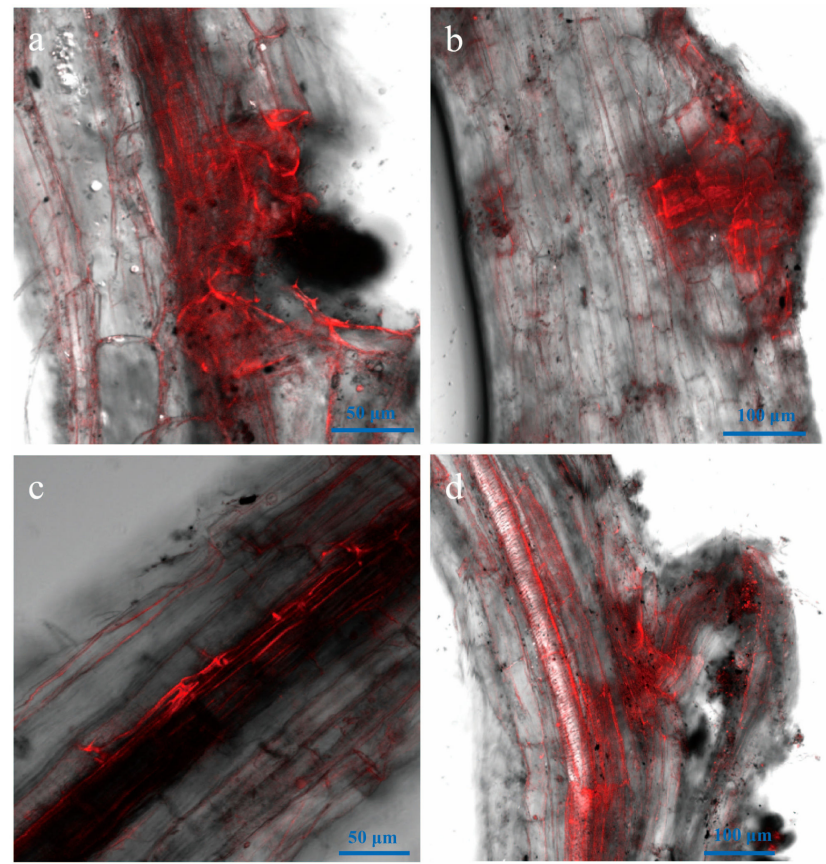

Figure 5. LSCM of hyphal colonization of root vessels from four to six dpi. $(\mathbf{a}, \mathbf{b})$ four dpi; $(\mathbf{c}, \mathbf{d})$ five and six dpi. 


\subsection{Vd-m Extensively Colonized Root Tissues}

Hyphal colonization of the root gradually increased from seven to ten dpi (Figure 6). Hyphae were growing in the cortex and in the neighboring parenchymal tissues (Figure 6a,b). The hyphae formed a dense network and surrounded the epidermal cell wall. The root xylem vessels were also filled with hyphae (Figure $6 c, d$ ). In cross and longitudinal sections, hyphae were clearly observed in the cortex and xylem vessels (Figure 6e,f).
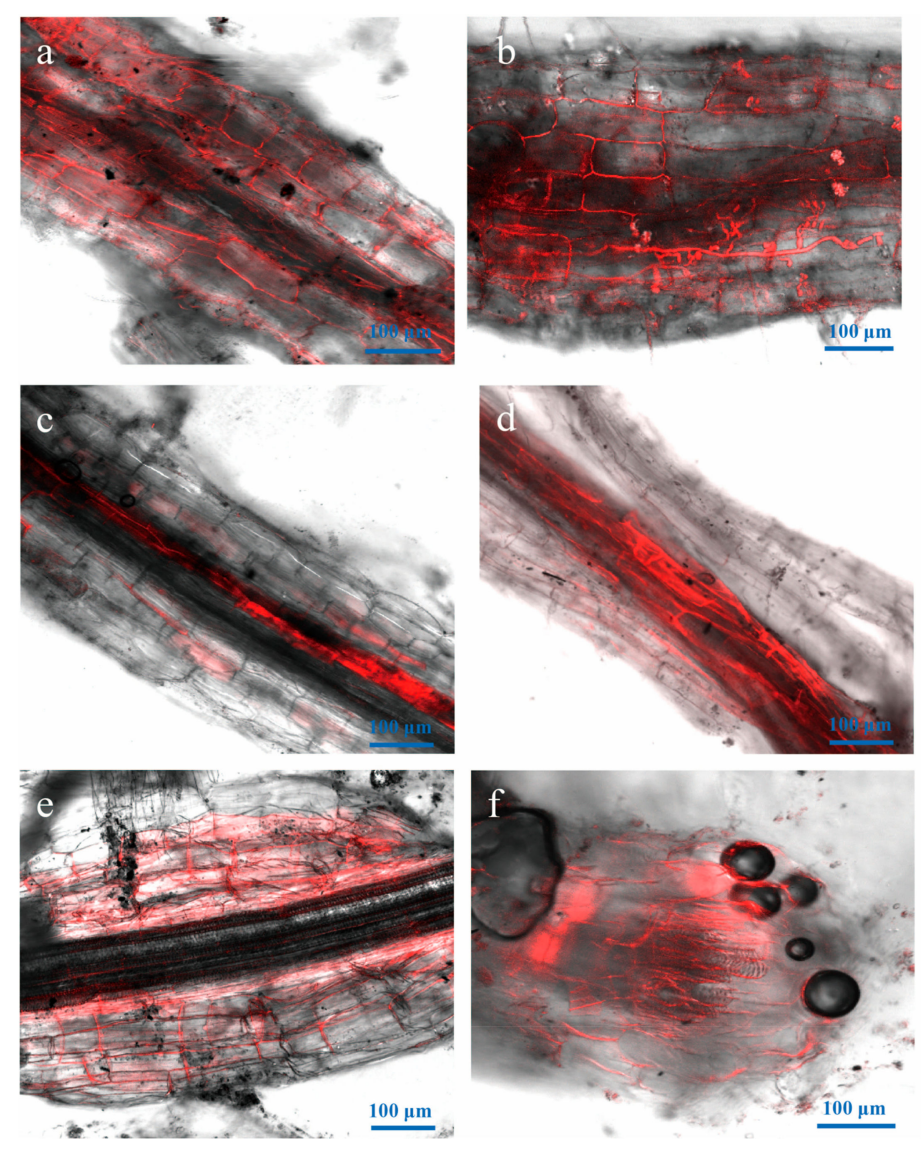

Figure 6. LSCM of colonization inside the root vessels from seven to ten dpi. (a,b) Extensive hyphal colonization of root tissue and $(\mathbf{c}, \mathbf{d})$ xylem vessels. (e,f) Cross and longitudinal sections of roots showing extensive hyphal network.

\subsection{Microscopic Examination of Leaves}

Once $V$. dahliae had colonized the host roots, the hyphae extended through the cortex and xylem vessels of the stem into the leaves. From eight to ten dpi, disease severity and leaf necrosis rapidly increased, and hyphae had spread throughout the plants. By ten dpi, the seedlings had wilted completely. In the leaf petiole, hyphae accumulated extensively (Figure 7a) and grew along the leaf veins, but were not detected in the leaf mesophyll (Figure $7 \mathrm{~b}$ ). 

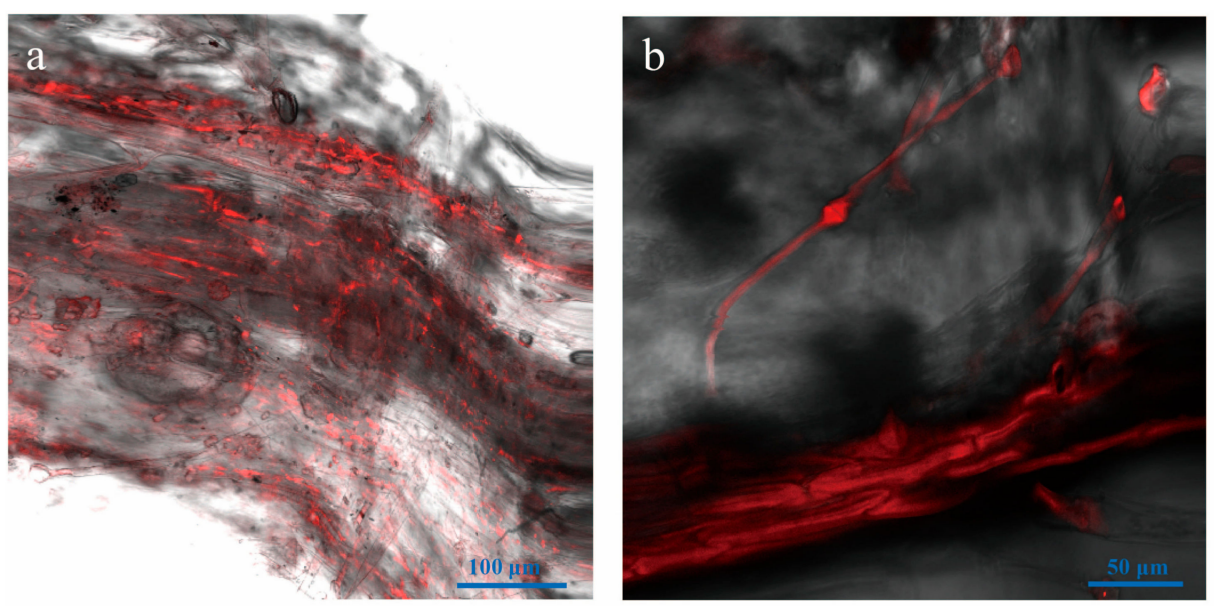

Figure 7. LSCM of hyphal colonization in leaves at ten days after inoculation of roots of N. benthamiana with $V d-m$. (a) Leaf petiole and (b) veins.

\subsection{Fungal Biomass at Different Stages}

When we estimated the relative quantity of fungal DNA in roots, stems, and leaves of $N$. benthamiana from six to ten dpi (Figure 8), roots had the most of fungal biomass, followed by stems and leaves. Fungal biomass increased over time in the different tissues, especially in the roots, and reached a maximum at ten dpi. These results were consistent with disease severity and phenotype of the $V d$ - $m$-inoculated seedlings.

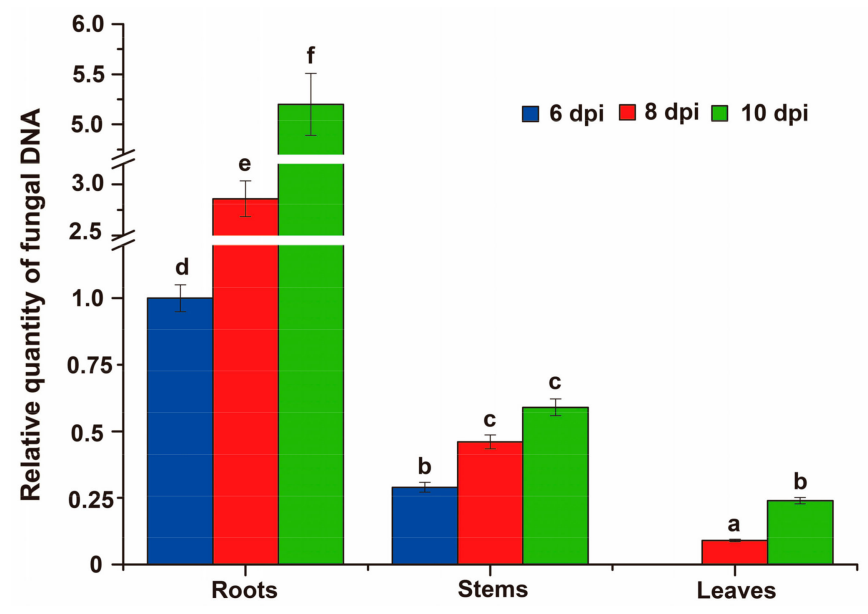

Figure 8. Quantitative real time polymerase chain reaction (qRT-PCR) quantification of fungal DNA extracted from root, stem, or leaves of seedlings of $N$. benthamiana at six, eight, and ten days after inoculation with $V d-m$. Fungal biomass was determined using ITS1 and ITS2 of $V$. dahliae ribosomal DNA relative to the referenced Nbactin gene. Error bars represent standard errors calculated for three independent replicates. Different letters indicate significant differences among the tissues, as determined with a least significant difference (LSD) test $(p<0.01)$.

\section{Discussion}

For the expression of green and red fluorescent proteins in fungi to directly observe the pathogenic process [38], a high-efficiency expression system of exogenous genes, including promoter and terminator, requires optimization and selection $[39,40]$. The CDS of the targeted gene should be optimized according to the codon preference of the species to be transformed [41,42]. An expression cassette, comprising cytidine deaminase, maize-codon optimized Cas9n, and uracil DNA glycosylase, was inserted into Arabidopsis to generate gain-of-function mutations [43]. Codon-optimized GFP has been effectively expressed in the cytoplasm and nuclei of Paramecium caudatum to visualize protein 
trafficking and localization [44]. The optimized sequences of genes for reporter molecules GFP, near-infrared fluorescent protein (iRFP), and mCherry, were expressed in Lactoccocus lactis [45]. In our previous experiment, we constructed RFP-labeled $V$. dahliae, but the red fluorescence was not strong and did not meet experimental requirements because of the lack of codon optimization. Here, thus, we optimized the CDS of $m$ Cherry and constructed the expression cassette using the $\operatorname{Tr} p C$ promoter and $\operatorname{Tr} p C$ terminator from $A$. nidulans. In addition, we inserted the Kozak sequence, which contributes to the translation of mRNA for the mCherry protein.

In a previous study, we developed a protoplast transformation system for $V$. dahliae that is quicker and easier than Agrobacterium tumefaciens-mediated transformation [36]. Using the present method for optimization, pCT-HM was introduced into $V$. dahliae. The transformants, primarily screened using LSCM and a selective medium, were confirmed by PCR. After six subcultures of the transformants, we selected one strain for subsequent experiments. Bright red fluorescence was clearly visible from the spores and hyphae. To ensure that the insertion of a foreign gene did not alter the pathogenicity of the $m$ Cherry-labeled fungus, we compared hyphal growth rate, sporulation abundance, and pathogenicity to the wild type strain to ensure that it did not obviously differ in growth traits, pathogenicity, or virulence. Previous studies have addressed this issue of whether the transformation of a foreign gene has any effect on the pathogenicity of an organism [46,47]. Although virulence was almost the same for eGFP (enhanced Green Fluorescent Protein) transformants and wild-type Aspergillus carbonarius, the eGFP transformant produced more ochratoxin A [48]. Similarly, the production of extracellular enzymes and fumonisin B did not differ in the GFP- and DsRed-labeled transformants of Fusarium verticillioides, respectively, compared with the wild type [46]. In our study, the insertion of the $m$ Cherry gene had no significant effect on the virulence of $V d-m$. Thus, the $V d-m$ strain is suitable for investigating the pathogenicity mechanism in N. benthamiana.

As a soil-borne fungus, $V$. dahliae infects the host through the roots [14,49]. However, its infection process in many host plants is still unclear. In a study of infection of cotton, the fungus infected the root tips, and colony density was low on the root surface [50]. Once $V$. dahliae colonized and invaded the root meristematic tissues, the spores began to germinate in the vascular bundles [19]. The hyphae of $V$. dahliae primarily entwine the outside of root hairs tightly by $24 \mathrm{~h}$ post inoculation (hpi) and elongate on the root hair surface, extending toward the root surface of Brassica napus. No specific infection structures are formed during fungal penetration of the root epidermis [51]. In contrast, by $48 \mathrm{hpi}$, appressoria had developed on lettuce roots, and the fungus penetrated the adjacent cell of the lettuce root [12]. After spore germination, the apex of some hyphae differentiate into simple penetration structures, hyphopodia, which adhere to the root surface [52]. Penetration pegs are then generated at the bottom of hyphopodia [53]. Hyphae cover the root surface without any apparent preference for a specific part of the root in Arabidopsis and cotton [16]. Root hairs, root caps of lateral roots, and root elongation zones of sunflower are covered by $V$. dahliae mycelium between 24 and 96 hpi [17].

In the present study, we used $V d-m$ to monitor the pathogenic process in $N$. benthamiana for the first time. At one dpi, spores on the main and lateral roots were swollen and had begun to germinate on the root surface. As the hyphae elongated, the fungus penetrated the epidermal cells and grew along the longitudinal vessels. Regardless of the part infected and type of growth, hyphae invaded the host quickly through root wounds and lateral root primordium, then intensely aggregated at these sites. After that, the hyphae quickly grew and began to enter into the xylem in roots.

$V$. dahliae hyphae form a network on the epidermal cells and around the cell wall, rather than penetrating the cells [53] as we found here. In addition, hyphae quickly grew in the xylem and filled the vascular tissue in roots, stems, and leaves. In the leaves, hyphae were detected in the petiole and veins, rather than mesophyll tissue. A similar pattern was observed for Verticillium longisporum, and fungal DNA and extensive microsclerotia accumulated in the petiole of Arabidopsis [54]. In C. coggygria, fungal DNA of $V$. dahliae is present in stems by six dpi, in branches by $12 \mathrm{dpi}$, and leaves by $14 \mathrm{dpi}$ [18]. Compared with stems and leaves, the roots have distinctly more fungal biomass, consistent with the initial colonization of the root and growth into the vascular bundles and subsequent invasion of the 
stems and leaves $[9,16]$. In sunflower, $V$. dahliae spreads into the vascular bundles and cortical tissues, leaf veins, and eventually pollens and seeds [17]. Overall, in this systemic disease of the vascular tissue, the spores colonize the root surface and penetrate the epidermal cells. Hyphae predominantly survive in the xylem during the pathogenic process, obtaining nutrients such as sugars, inorganic salts, and amino acids [55].

\section{Conclusion}

In this study, the CDS of $m$ Cherry was optimized, and the expression cassette was constructed based on $V$. dahliae codon preference. The pCT-HM was introduced into fungal protoplasts to generate $V d-m$ strains that produce a bright red fluorescence. Using LSCM and the $V d-m$ strain, we clearly visualized the infection, colonization, and systemic development of $V$. dahliae in $N$. benthamiana. In future studies, this optimized mCherry system could be linked with a targeted gene to facilitate subcellular localization. Moreover, the $V d-m$ strain is exceedingly valuable for further investigating the pathogenic process in detail and fungal interactions with host plants.

Supplementary Materials: The following are available online at http:/ / www.mdpi.com/2073-4425/9/10/508/s1, Figure S1. Alignment and amino acid sequences of $m$ Cherry sequence. The original and optimized sequences were aligned with the program DNAMAN. Differing nucleotides are represented in red. Figure S2. PCR detection of hpt (549 bp) and mCherry (427 bp) genes, confirming exogenous tDNA integration into $V$. dahliae genomic DNA. Figure S3. Biological characteristics of $V d-m$ and $V d$-wt. (a) Colony diameter on PDA plates after three, six, nine, and 12 days. (b) Spore production in shake culture on Czapek-Dox medium after four, five, six and seven days. (c) Disease index of $N$. benthamiana at eight, nine, and $10 \mathrm{dpi}$.

Author Contributions: H.C. and H.G. conceived and designed the experiments. X.S., G.L., L.R., X.L., and L.S. performed experiments and analyzed data.

Acknowledgments: This research was supported by a grant from the National Natural Science Foundation of China (31772244 and 31701861), the special fund for agro-scientific research in the public interest (201503109), and the Agricultural Science and Technology Innovation Program of CAAS.

Conflicts of Interest: The authors declare they have no conflict of interest.

\section{References}

1. Pegg, G.F.; Brady, B.L. Verticillium Wilts; CABI Publishing: Oxford, UK, 2002; pp. 142-166.

2. Hu, D.; Wang, C.; Tao, F.; Cui, Q.; Xu, X.; Shang, W.; Hu, X. Whole genome wide expression profiles on germination of Verticillium dahliae microsclerotia. PLoS ONE 2014, 9, e100046. [CrossRef] [PubMed]

3. Farley, J.D.; Wilhelm, S.; Snyder, W.C. Repeated germination and sporulation of microsclerotia of Verticillium albo-atrum in soil. Phytopathology 1971, 61, 260-264. [CrossRef]

4. Duressa, D.; Rauscher, G.; Koike, S.T.; Mou, B.; Hayes, R.J.; Maruthachalam, K.; Subbarao, K.V.; Klosterman, S.J. A real-time PCR assay for detection and quantification of Verticillium dahliae in spinach seed. Phytopathology 2012, 102, 443-451. [CrossRef] [PubMed]

5. Vallad, G.E.; Bhat, R.G.; Koike, S.T.; Ryder, E.J.; Subbarao, K.V. Weedborne reservoirs and seed transmission of Verticillium dahliae in lettuce. Plant Dis. 2007, 89, 317-324. [CrossRef]

6. Bubici, G.; Cirulli, M. Verticillium wilt of olive: Current status, disease management and future prospects. Prot. Delle Colt. 2012, 4, 42-56.

7. Rowe, R.C.; Davis, J.R.; Powelson, M.L.; Rouse, D.I. Potato early dying: Causal agents and management strategies. Plant Dis. 1987, 71, 482-489. [CrossRef]

8. López-Escudero, F.J.; Mercado-Blanco, J. Verticillium wilt of olive: A case study to implement an integrated strategy to control a soil-borne pathogen. Plant Soil 2010, 344, 1-50. [CrossRef]

9. Rehman, L.; Su, X.; Li, X.; Qi, X.; Guo, H.; Cheng, H. FreB is involved in the ferric metabolism and multiple pathogenicity-related traits of Verticillium dahliae. Curr. Genet. 2018, 64, 645-659. [CrossRef] [PubMed]

10. Mol, L.; Riessen, H.W.V. Effect of plant roots on the germination of microsclerotia of Verticillum dahliae. Eur. J. Plant Pathol. 1995, 101, 673-678. [CrossRef]

11. Fradin, E.F.; Thomma, B.P. Physiology and molecular aspects of Verticillium wilt diseases caused by V. dahliae and V. albo-atrum. Mol. Plant Pathol. 2006, 7, 71-86. [CrossRef] [PubMed] 
12. Vallad, G.E.; Subbarao, K.V. Colonization of resistant and susceptible lettuce cultivars by a green fluorescent protein-tagged isolate of Verticillium dahliae. Phytopathology 2008, 98, 871-885. [CrossRef] [PubMed]

13. Iakovoss, P.; Sotiriose, T.; Ioannisa, S.; Iordanis, C.; Epaminondasj, P. Mode of action of a non-pathogenic Fusarium oxysporum strain against Verticillium dahliae using Real Time QPCR analysis and biomarker transformation. Biol. Control 2009, 50, 30-36. [CrossRef]

14. Huisman, O. Interrelations of root growth dynamics to epidemiology of root-invading fungi. Annu. Rev. Phytopathol. 1982, 20, 303-327. [CrossRef]

15. Evans, G.; Gleeson, A.C.; Evans, G.; Gleeson, A.C. Observations on the origin and nature of Verticillium dahliae colonizing plant roots. Aust. J. Biol. Sci. 1973, 26, 151-162. [CrossRef]

16. Zhao, P.; Zhao, Y.L.; Jin, Y.; Zhang, T.; Guo, H.S. Colonization process of Arabidopsis thaliana roots by a green fluorescent protein-tagged isolate of Verticillium dahliae. Protein Cell 2014, 5, 94-98. [CrossRef] [PubMed]

17. Zhang, Y.; Zhang, J.; Gao, J.; Zhang, G.; Yu, Y.; Zhou, H.; Chen, W.; Zhao, J. The colonization process of sunflower by a green fluorescent protein-tagged isolate of Verticillium dahliae and its seed transmission. Plant Dis. 2018, 102, 1772-1778. [CrossRef] [PubMed]

18. Wang, Y.; Xiao, S.; Xiong, D.; Tian, C. Genetic transformation, infection process and qPCR quantification of Verticillium dahliae on smoke-tree Cotinus coggygria. Australas. Plant Pathol. 2012, 42, 33-41. [CrossRef]

19. Zhang, W.; Jiang, T.; Cui, X.; Qi, F.; Jian, G. Colonization in cotton plants by a green fluorescent protein labelled strain of Verticillium dahliae. Eur. J. Plant Pathol. 2013, 135, 867-876. [CrossRef]

20. Kendall, J.; Badminton, M. Aequorea victoria bioluminescence moves into an exciting new era. Trends Biotechnol. 1998, 16, 216-224. [CrossRef]

21. Meyer, A.J.; Dick, T.P. Fluorescent protein-based redox probes. Antioxid. Redox Signal. 2010, 13, 621-650. [CrossRef] [PubMed]

22. Lubeck, M.; Imb, K.; Jensen, B.; Thrane, U.; Janvier, C.; Jensen, D.F. GUS and GFP transformation of the biocontrol strain Clonostachys rosea IK726 and the use of these marker genes in ecological studies. Mycol. Res. 2002, 106, 815-826. [CrossRef]

23. Weid, I.V.D.; Artursson, V.; Seldin, L.; Jansson, J.K. Antifungal and root surface colonization properties of GFP-tagged Paenibacillus brasilensis PB177. World J. Microbiol. Biotechnol. 2005, 21, 1591-1597. [CrossRef]

24. Mansouri, S. Developing Novel Molecular Tools to Study the Fusarium virguliforme-Soybean Interaction. Master's Thesis, Southern Illinois University, Carbondale, IL, USA, 2007.

25. Huh, W.K.; Falvo, J.V.; Gerke, L.C.; Carroll, A.S.; Howson, R.W.; Weissman, J.S.; O'Shea, E.K. Global analysis of protein localization in budding yeast. Nature 2003, 425, 686-691. [CrossRef] [PubMed]

26. Skadsen, R.W.; Hohn, T.M. Use of Fusarium graminearum transformed with GFP to follow infection patterns in barley and Arabidopsis. Physiol. Mol. Plant Pathol. 2004, 64, 45-53. [CrossRef]

27. Mcdougal, R.; Yang, S.; Schwelm, A.; Stewart, A.; Bradshaw, R. A novel GFP-based approach for screening biocontrol microorganisms in vitro against Dothistroma septosporum. J. Microbiol. Methods 2011, 87, 32-37. [CrossRef] [PubMed]

28. Li, E.; Wang, G.; Yang, Y.; Xiao, J.; Mao, Z.; Xie, B. Microscopic analysis of the compatible and incompatible interactions between Fusarium oxysporum f. sp. conglutinans and cabbage. Eur. J. Plant Pathol. 2014, 141, 597-609. [CrossRef]

29. Su, X.; Rehman, L.; Guo, H.; Li, X.; Cheng, H. The oligosaccharyl transferase subunit STT3 mediates fungal development and is required for virulence in Verticillium dahliae. Curr. Genet. 2018, 64, 235-246. [CrossRef] [PubMed]

30. Sarrocco, S.; Falaschi, N.; Vergara, M.; Nicoletti, F.; Vannacci, G. Use of Fusarium oxysporum f. sp. dianthi transformed with marker genes to follow colonization of carnation roots. J. Plant Pathol. 2007, 89, 47-54. [CrossRef]

31. Monteiro, R.A.; Schmidt, M.A.; Baura, V.A.; Balsanelli, E.; Wassem, R.; Yates, M.G.; Randi, M.A.; Pedrosa, F.O.; Souza, E.M. Early colonization pattern of maize (Zea mays L. Poales, Poaceae) roots by Herbaspirillum seropedicae (Burkholderiales, Oxalobacteraceae). Genet. Mol. Biol. 2008, 31, 932-937. [CrossRef]

32. Ilgen, P.; Hadeler, B.; Maier, F.J.; Schäfer, W. Developing kernel and rachis node induce the trichothecene pathway of Fusarium graminearum during wheat head infection. Mol. Plant Microbe Interact. 2009, 22, 899-908. [CrossRef] [PubMed] 
33. Shaner, N.C.; Campbell, R.E.; Steinbach, P.A.; Giepmans, B.N.; Palmer, A.E.; Tsien, R.Y. Improved monomeric red, orange and yellow fluorescent proteins derived from Discosoma sp. red fluorescent protein. Nat. Biotechnol. 2004, 22, 1567-1572. [CrossRef] [PubMed]

34. Wang, X.; Qi, H.; Zhang, J.; Yangqi, G.; Tang, C. Transformation and selection of fluorescent protein gene labelled Verticillium dahliae. Cotton Sci. 2014, 26, 221-227.

35. Shrivastava, S.; Poddar, R.; Shukla, P.; Mukhopadhyay, K. Study of codon bias perspective of fungal xylanase gene by multivariate analysis. Bioinformation 2009, 3, 425-429. [CrossRef] [PubMed]

36. Rehman, L.; Su, X.; Guo, H.; Qi, X.; Cheng, H. Protoplast transformation as a potential platform for exploring gene function in Verticillium dahliae. BMC Biotechnol. 2016, 16, 57-65. [CrossRef] [PubMed]

37. Tzima, A.K.; Paplomatas, E.J.; Tsitsigiannis, D.I.; Kang, S. The G protein $\beta$ subunit controls virulence and multiple growth- and development-related traits in Verticillium dahliae. Fungal Genet. Biol. 2012, 49, 271-283. [CrossRef] [PubMed]

38. Lorang, J.M.; Tuori, R.P.; Martinez, J.P.; Sawyer, T.L.; Redman, R.S.; Rollins, J.A.; Wolpert, T.J.; Johnson, K.B.; Rodriguez, R.J.; Dickman, M.B. Green fluorescent protein is lighting up fungal biology. Appl. Environ. Microbiol. 2001, 67, 1987-1994. [CrossRef] [PubMed]

39. Turgeon, B.G.; Garber, R.C.; Yoder, C.O. Development of a fungal transformation system based on selection of sequences with promoter activity. Mol. Cell. Biol. 1987, 7, 3297-3305. [CrossRef] [PubMed]

40. Okuda, T.; Ando, A.; Sakuradani, E.; Kikukawa, H.; Kamada, N.; Ochiai, M.; Shima, J.; Ogawa, J. Selection and characterization of promoters based on genomic approach for the molecular breeding of oleaginous fungus Mortierella alpina 1S-4. Curr. Genet. 2014, 60, 183-191. [CrossRef] [PubMed]

41. Arazoe, T.; Miyoshi, K.; Yamato, T.; Ogawa, T.; Ohsato, S.; Arie, T.; Kuwata, S. Tailor-made CRISPR/Cas system for highly efficient targeted gene replacement in the rice blast fungus. Biotechnol. Bioeng. 2015, 112, 2543-2549. [CrossRef] [PubMed]

42. Zhang, C.; Meng, X.; Wei, X.; Lu, L. Highly efficient CRISPR mutagenesis by microhomology-mediated end joining in Aspergillus fumigatus. Fungal Genet. Biol. 2016, 86, 47-57. [CrossRef] [PubMed]

43. Chen, Y.; Wang, Z.; Ni, H.; Xu, Y.; Chen, Q.; Jiang, L. CRISPR/Cas9-mediated base-editing system efficiently generates gain-of-function mutations in Arabidopsis. Sci. China Life Sci. 2017, 60, 520-523. [CrossRef] [PubMed]

44. Takenaka, Y.; Haga, N.; Harumoto, T.; Matsuura, T.; Mitsui, Y. Transformation of Paramecium caudatum with a novel expression vector harboring codon-optimized GFP gene. Gene 2002, 284, 233-240. [CrossRef]

45. Martinezjaramillo, E.; Garzamorales, R.; Loeraarias, M.J.; Saucedocardenas, O.; Montesdeocaluna, R.; Mcnally, L.R.; Gomezgutierrez, J.G. Development of Lactococcus lactis encoding fluorescent proteins, GFP, $m$ Cherry and iRFP regulated by the nisin-controlled gene expression system. Stain Technol. 2017, 92, 167-174. [CrossRef]

46. Wu, L.; Conner, R.L.; Wang, X.; Xu, R.; Li, H. Variation in growth, colonization of maize, and metabolic parameters of GFP- and DsRed-labeled Fusarium verticillioides strains. Phytopathology 2016, 106, 890-899. [CrossRef] [PubMed]

47. Duncan, K.E.; Howard, R.J. Biology of maize kernel infection by Fusarium verticillioides. Mol. Plant-Microbe Interact. 2010, 23, 6-16. [CrossRef] [PubMed]

48. Crespo-Sempere, A.; López-Pérez, M.; Martínez-Culebras, P.V.; González-Candelas, L. Development of a green fluorescent tagged strain of Aspergillus carbonarius to monitor fungal colonization in grapes. Int. J. Food Microbiol. 2011, 148, 135-140. [CrossRef] [PubMed]

49. Griffiths, D.A. The development of lignitubers in roots after infection by Verticillium dahliae Kleb. Can. J. Microbiol. 1971, 17, 441-444. [CrossRef] [PubMed]

50. Gerik, J.S.; Huisman, O.C. Study of field-grown cotton roots infected with Verticillium dahliae using an immunoenzymatic staining technique. Phytopathology 1988, 78, 1174-1178. [CrossRef]

51. Eynck, C.; Koopmann, B.; Grunewaldt-Stoecker, G.; Karlovsky, P.; von Tiedemann, A. Differential interactions of Verticillium longisporum and V. dahliae with Brassica napus detected with molecular and histological techniques. Eur. J. Plant Pathol. 2007, 118, 259-274. [CrossRef]

52. Reusche, M.; Truskina, J.; Thole, K.; Nagel, L.; Rindfleisch, S.; Tran, V.T.; Braus-Stromeyer, S.A.; Braus, G.H.; Teichmann, T.; Lipka, V. Infections with the vascular pathogens Verticillium longisporum and Verticillium dahliae induce distinct disease symptoms and differentially affect drought stress tolerance of Arabidopsis thaliana. Environ. Exp. Bot. 2014, 108, 23-37. [CrossRef] 
53. Zhao, Y.L.; Zhou, T.T.; Guo, H.S. Hyphopodium-epecific VdNoxB/VdPls1-dependent ROS-Ca ${ }^{2+}$ signaling is required for plant infection by Verticillium dahliae. PLoS Pathog. 2016, 12, e1005793. [CrossRef] [PubMed]

54. Ralhan, A.; Schottle, S.; Thurow, C.; Iven, T.; Feussner, I.; Polle, A.; Gatz, C. The vascular pathogen Verticillium longisporum requires a jasmonic acid-independent COI1 function in roots to elicit disease symptoms in Arabidopsis shoots. Plant Physiol. 2012, 159, 1192-1203. [CrossRef] [PubMed]

55. Dimond, A.E. Biophysics and biochemistry of the vascular wilt syndrome. Annu. Rev. Phytopathol. 1970, 8, 301-322. [CrossRef]

(C) 2018 by the authors. Licensee MDPI, Basel, Switzerland. This article is an open access article distributed under the terms and conditions of the Creative Commons Attribution (CC BY) license (http:/ / creativecommons.org/licenses/by/4.0/). 